\title{
CAPACIDADES DAS INSTITUIÇÕES MUNICIPAIS DE PROTEÇÃO E DEFESA CIVIL NO BRASIL: DESAFIOS E PERSPECTIVAS
}

\author{
Luciana de Resende Londe ${ }^{1}$ \\ Erico Soriano ${ }^{2}$ \\ Marcos Pellegrini Coutinho ${ }^{3}$
}

RESUMO: Há vários desafios para a atuação dos órgãos de Proteção e Defesa Civil no Brasil. Procuramos traçar um panorama destes órgãos através de questionários direcionados aos seus agentes, e, também, identificar perspectivas de ações baseadas na legislação e nas diretrizes de gestão de risco de desastres no país. Verificamos que os agentes entendem ações relacionadas aos desastres socioambientais como sua principal atribuição, priorizando ações preventivas. Dificuldades comumente verificadas, como falta de equipamentos, instalações físicas precárias e baixa remuneração, não foram apontadas na pesquisa como os principais obstáculos para a realização dos trabalhos. Destaca-se, entretanto, a falta de apoio institucional, mencionada em $23,2 \%$ das respostas. O maior e mais importante desafio, entretanto, é a interação com a comunidade, crucial para o bom funcionamento da Defesa Civil.

Palavras-chave: defesa civil, desastres socioambientais; gestão de risco de desastres; Lei 12.608/12; identidade profissional.

\section{CAPABILITIES OF CIVIL DEFENSE INSTITUTIONS IN BRAZILIAN MUNICIPALITIES: CHALLENGES AND VIEWS}

ABSTRACT: Brazilian Civil Defense institutions face many challenges. We have built a scenario through queries answered by Civil Defense professionals and identified perspectives for action based on Brazilian Law 12.608/12 and disaster risk management guidelines. Professionals understand actions towards societal-environmental disasters as their main role. They prioritize preparedness instead of response. In the query, common problems, such as lack of devices, poor structure and low payment, were not recognized as the main obstacle to an effective work. 23,2\% of the answers highlight lack of institutional support as their main difficulty. Interaction with community appears as the main challenge.

Keywords: civil defense; societal/environmental disasters; disaster risk reduction; Brazilian Law 12.608/12; professional identity.

1. Centro Nacional de Monitoramento e Alertas de Desastres Naturais (luciana.londe@cemaden.gov.br).

2. Departamento de Ciência da Informação da Universidade Federal de São Carlos (ericogeo@gmail.com).

3. Centro Nacional de Monitoramento e Alertas de Desastres Naturais (marcos.coutinho@cemaden.gov.br). 


\section{INTRODUÇÃO}

As instituições de Proteção e Defesa Civil, em diferentes níveis (municipal, estadual e federal), são parte crucial do sistema de prevenção e resposta a desastres no Brasil.

A Defesa Civil como conhecemos hoje teve sua origem durante a Segunda Guerra Mundial, para prover ações sistematizadas de segurança e proteção durante os bombardeios alemães à cidade de Londres (GORGULHO, 2006), tendo por isto recebido o nome de "defesa". No Brasil, o propósito inicial foi sendo modificado durante o desenvolvimento da instituição, conferindo importância à proteção da sociedade contra os riscos associados à ocorrência de desastres e a atividades de resposta aos desastres concretizados (Figura 01).

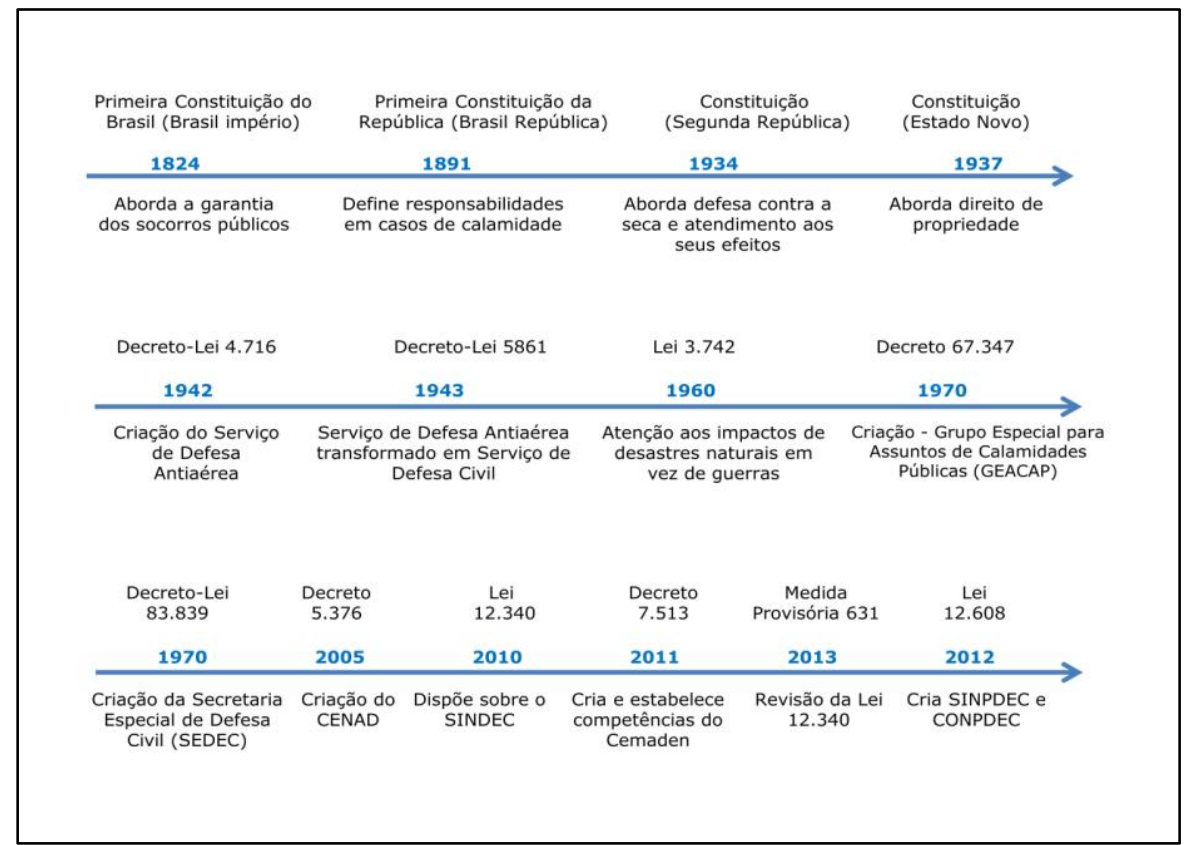

FIGURA 01: Evolução da Defesa Civil no Brasil. Fonte: UFSC/CEPED (2013). Fonte: UFSC/CEPED (2013).

Organização: Luciana R. Londe (2015).

A criação do órgão de Defesa Civil brasileiro ocorreu na década de 1940 e a proposta de considerar a Defesa Civil como instituição estratégica para redução de riscos de desastres ocorreu com a organização do Sistema Nacional de Defesa Civil, no Decreto no 97.274, de 16/12/1988 (Ministério da Integração Nacional). Este decreto, revogado pelo de $\mathrm{n}^{\circ} 895$, 16/08/1993 instituiu o Sistema Nacional de Defesa Civil (SINDEC) no país. De acordo com o Art. $3^{\circ}$, inciso I, a defesa civil é "o conjunto de ações preventivas, de socorro, assistenciais e recuperativas destinadas a evitar ou minimizar os desastres, preservar o moral da população e restabelecer a normalidade social".

O SINDEC evoluiu para o Sistema Nacional de Proteção e Defesa Civil - SINPDEC, a partir da Lei 12.608/12. É composto por "órgãos e entidades da Administração pública federal, dos estados, do Distrito Federal e dos municípios e pelas entidades públicas e privadas de atuação significativa na área de proteção e defesa civil" (BRASIL, 2012), cabendo à Secretaria Nacional de Proteção e Defesa Civil (SEDEC) a responsabilidade de coordenar as ações de proteção e defesa civil no território nacional (MI, 2014). "Tem por finalidade contribuir no 
processo de planejamento, articulação, coordenação e execução dos programas, projetos e ações de proteção e defesa civil" (BRASIL, 2012).

A lei 12.608/12 também instituiu a Política Nacional de Proteção e Defesa Civil - PNPDEC, dispôs sobre o Conselho Nacional de Proteção e Defesa Civil - CONPDEC e autorizou a criação de um sistema de informações e monitoramento de desastres.

Também através desta lei, as ações de proteção e Defesa Civil no Brasil estão previstas e estruturadas nas esferas nacional, estadual e municipal. Como os desastres acontecem localmente, assim como as atividades emergenciais de resposta a estes desastres, é importante que os órgãos municipais de Proteção e Defesa Civil estejam preparados e bem estruturados, atuando em parceria com outros órgãos locais e regionais e com a comunidade em situação de risco.

O nível de preparação da Defesa Civil municipal é que determina o comportamento diante de um desastre, ou seja, determina se o município terá condições de abrigar, agasalhar e alimentar a população atingida, se será capaz de mobilizar a melhor força de trabalho no menor tempo, se terá agilidade para pedir auxílio externo e se saberá a quem recorrer ( $p$ : 16).

Vários aspectos interferem no funcionamento dos órgãos municipais de Proteção e Defesa Civil: estrutura física (instalações, viaturas, sistemas de comunicação, recursos), corpo profissional (incluindo qualificação adequada, treinamento, motivação) e interação com outros órgãos envolvidos na prevenção e resposta aos desastres. "A Defesa Civil bem estruturada é a certeza de que essas ameaças, quando concretizadas, serão minimizadas" (BRAUN, 2006: 14).

A estruturação efetiva da Defesa Civil deve ser permeada por conhecimento técnico, com profissionais capacitados e instruídos para trabalhar na prevenção de desastres e prontos para enfrentá-los, o que consiste em medidas de curta e longa duração, planejadas para salvar vidas e limitar os danos que possam ser causados (BRAUN, 2006).

Embora se configure como o principal órgão público para mitigar as consequências de um desastre, a Defesa Civil apresenta uma série de dificuldades estruturais e de recursos que limitam suas ações (SORIANO, 2012). Motivados pela necessidade de conhecer os desafios da Defesa Civil Brasileira com foco no nível local, procuramos neste trabalho traçar um panorama dos órgãos municipais de Defesa Civil, através de questionários direcionados aos profissionais destes órgãos, e, também, identificar perspectivas de ações baseadas na legislação e nas diretrizes de gestão de risco de desastres no país.

\section{MATERIAL E MÉTODO}

Entendemos que os profissionais que atuam nos órgãos de Proteção e Defesa Civil são as pessoas mais indicadas para relatar e avaliar as dificuldades e limitações encontradas em sua atuação. Partindo desta premissa, elaboramos o questionário reproduzido no Apêndice I. Este questionário foi publicado na internet através do recurso de "formulários" da plataforma "Google Drive".

Em seguida, enviamos mensagens eletrônicas, via conta de e-mail institucional, a representantes de órgãos municipais de Proteção e Defesa Civil com um breve 
esclarecimento sobre o trabalho e um convite para o preenchimento do questionário de forma voluntária e anônima. Optamos pelo anonimato para que os profissionais de Defesa Civil não tivessem receio de apontar as fragilidades da instituição, desta forma promovendo respostas mais próximas da realidade.

Os convites foram enviados em semanas diferentes para cada região do país, para incentivar a participação de todas as regiões, apesar de não podermos quantificar a origem das respostas devido ao caráter sigiloso do questionário. Alguns convites foram reforçados para garantir a representatividade dos diferentes estados.

Obtivemos 150 questionários respondidos de forma completa e realizamos a tabulação dos dados quantificáveis e a análise das respostas com base no referencial teórico e bibliográfico.

\section{RESULTADOS E DISCUSSÃO}

O Ciclo de Gestão em Proteção e Defesa Civil (BRASIL, 2012; ESTRATÉGIA, 2009) geralmente conta com as seguintes etapas: prevenção, mitigação, preparação, resposta, recuperação e reconstrução. Pode haver variações na definição destas etapas de acordo com a literatura adotada, mas é consensual a ideia de que a Gestão de Riscos de Desastres deve contar com ações antes, durante e após a ocorrência de um desastre, de modo contínuo, para a redução efetiva dos riscos e da vulnerabilidade.

A etapa de Prevenção prevê ações para reduzir a ocorrência e a intensidade de desastres, por meio da identificação, mapeamento e monitoramento de riscos, ameaças e vulnerabilidades locais, incluindo a capacitação da sociedade em atividades de defesa civil, entre outras estratégias estabelecidas pelo Ministério da Integração (BRASIL, 2010).

As atividades de prevenção podem reduzir consideravelmente o total de mortos e feridos durante um desastre, mas geralmente não recebem a devida importância. Considera-se, entre outros fatores, o pequeno efeito midiático das mesmas: geralmente são grandes obras, em vez de atividades educativas, que conferem reconhecimento aos secretários e prefeitos municipais. Segundo Valencio e Valencio (2010, n.p.),

A atual ineficácia das ações de prevenção e preparação resultou no dispêndio de um bilhão de reais para refazer obras em vários estados da federação, quando poderia ser um montante destinado a novos investimentos, isso, num contexto de crise financeira global.

Vários fatores interferem na eficiência de ações preventivas ou de planejamentos inseridos na gestão de riscos de desastres, mas entendemos que há uma pergunta importante a ser respondida no início deste processo: o que é realmente atribuição da Defesa Civil? Em conversas pessoais com profissionais de diferentes municípios e estados, percebemos uma confusão de papéis, principalmente com relação ao Corpo de bombeiros e à Guarda Municipal.

Alguns municípios incluem entre as ações de Defesa Civil o atendimento a peculiaridades locais, como corte de árvores, questões de ordenamento urbano (remoção de instalações não autorizadas pela prefeitura, por exemplo), questões relacionadas a moradores de rua e, em áreas litorâneas, envolvimento na manutenção da ordem nas praias. 
Em resposta ao questionário, os itens mais citados como atribuições da Defesa Civil municipal foram aqueles relacionados aos desastres socioambientais, principalmente à interdição de construções inseguras ou construídas em áreas de risco (Figura 2A). É interessante observar que as operações de resgate e salvamento (ações de enfrentamento dos desastres) foram menos mencionadas que as ações preventivas, como remoção, interdição e orientação da população.

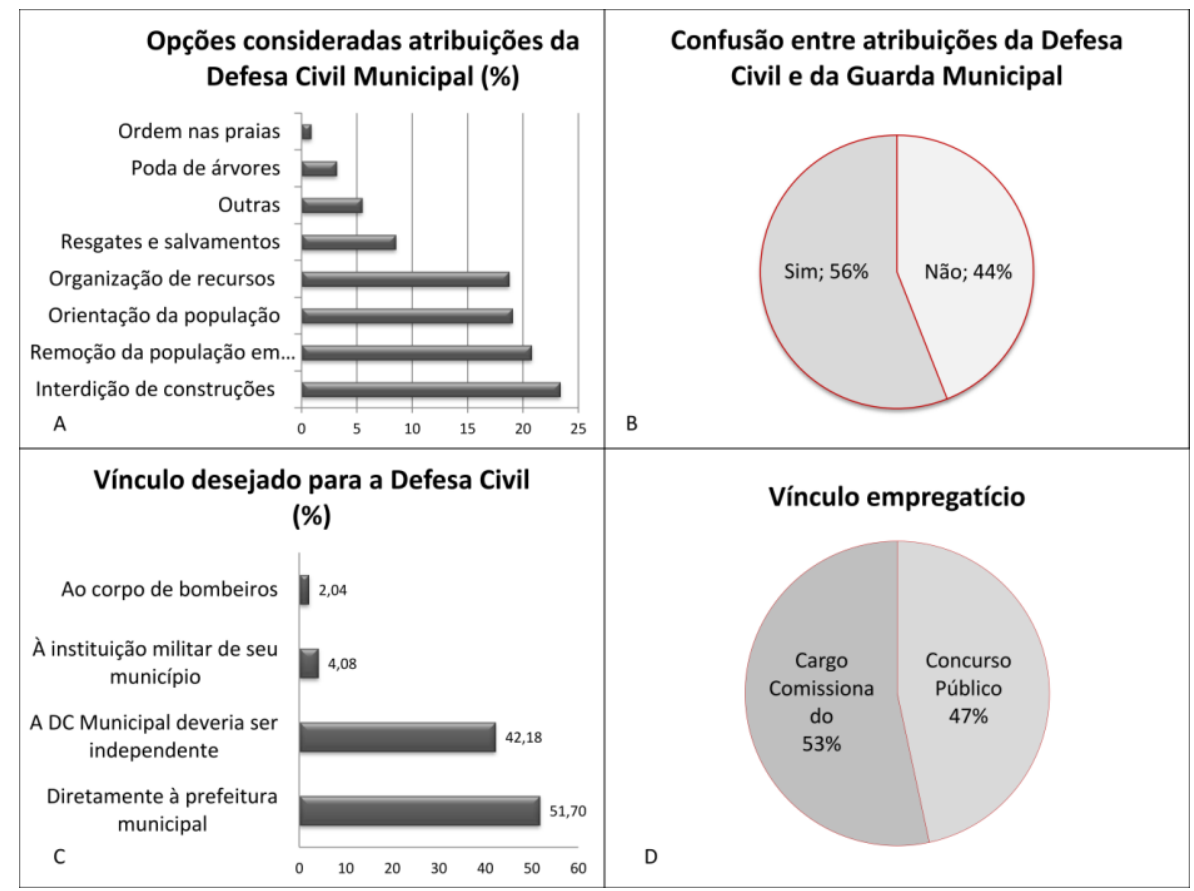

FIGURA 02: Respostas relacionadas à identidade institucional. Reprodução completa do questionário no Anexo l, questões 1 (a), 3(b), 16(c) e 20(d).

Mais da metade dos entrevistados acredita que a população confunde as atribuições da Defesa Civil com as da Guarda Municipal (Figura 2B), indicando a necessidade de atividades informativas e de orientação quanto à atribuição de papéis. No universo pesquisado, $53 \%$ dos municípios contam com Guarda Municipal.

Além da população, entendemos que os próprios municípios ainda estão confusos sobre a adequação e hierarquia da defesa civil. Em alguns locais, alguns membros da Defesa Civil são militares. Em outros, fazem parte do departamento de trânsito e, em outros, estão integrados ao departamento de meio ambiente. Para $51,7 \%$ dos entrevistados, o órgão municipal de Defesa Civil deveria estar subordinado diretamente à Prefeitura Municipal e para 42,2\% a Defesa Civil Municipal deveria ser independente (Figura 2C).

Mais de $70 \%$ dos entrevistados julgam que "a atribuição de cargos por indicação está incorreta e as alterações do quadro de profissionais trazem prejuízos à atuação da defesa civil e, portanto, os cargos deveriam ser preenchidos através de concurso público" (Figura $3 B$ ). No mesmo universo pesquisado, 53\% dos entrevistados tem vínculo com a Defesa Civil Municipal através de cargo comissionado (Figura 2D).

Já os dados do perfil municipal (MUNIC/IBGE 2013) mostram que, dos 5.570 municípios, 94,77 \% responderam não ou não aplicável possuir Defesa Civil com plano de carreira própria. Contudo, 50 \% apresentam COMPDEC, fato que revela a importância dessa instituição, mesmo que os funcionários não tenham plano de carreira. A existência de 
COMPDECs sem estrutura e plano de carreira também pode justificar-se como formalidade para acessar recursos em caso de desastres.

É importante ressaltar que o Artigo 18 da lei 12.608/12 considera agentes de proteção e defesa civil não apenas os agentes políticos e públicos, mas também os agentes voluntários. De acordo com o parágrafo único deste artigo: "Os órgãos do SINPDEC adotarão, no âmbito de suas competências, as medidas pertinentes para assegurar a profissionalização e a qualificação, em caráter permanente, dos agentes públicos referidos no inciso III". (BRASIL, 2012)

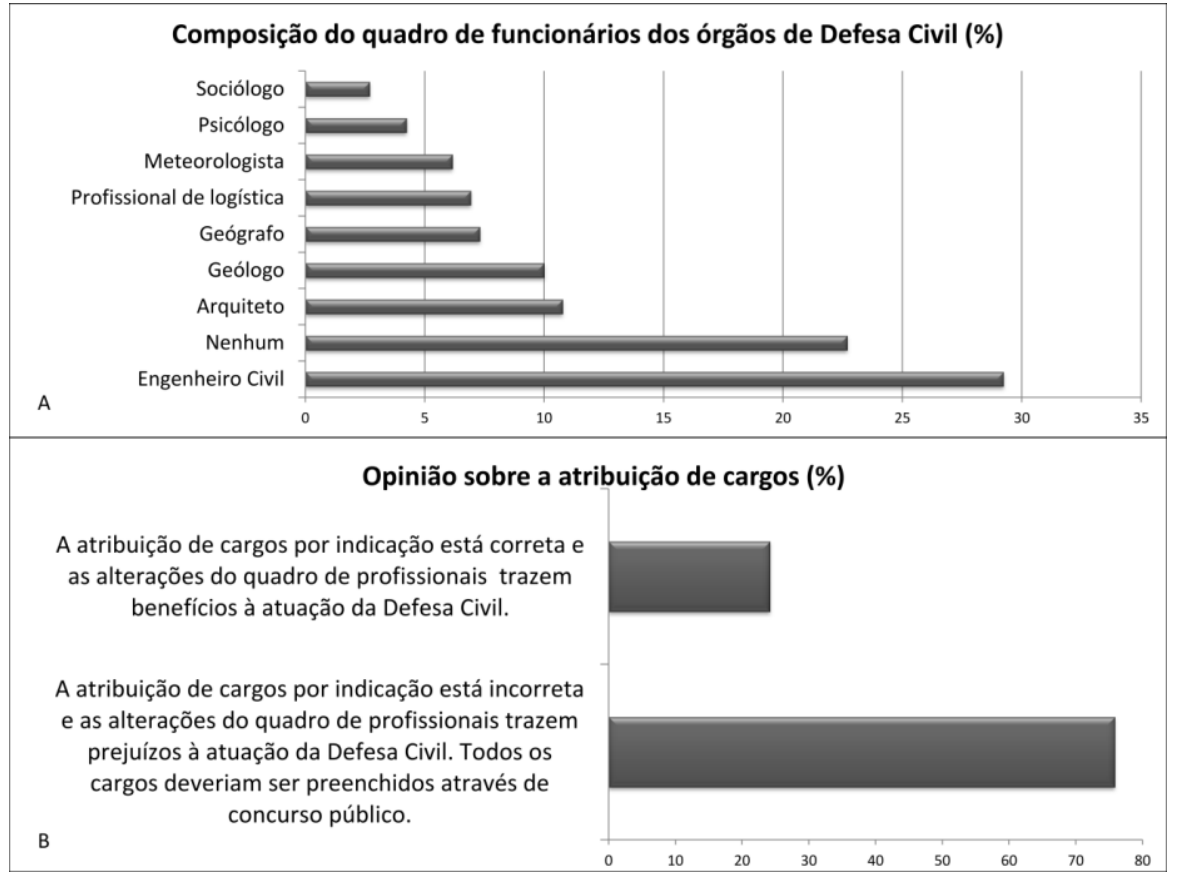

FIGURA 03: Respostas relacionadas à identidade institucional. Reprodução completa do questionário no Anexo I, questões 6 (a) e 15(b).

Entendemos que uma Defesa Civil com funcionários capacitados e com plano de carreira seja capaz de mudar a situação atual, onde prevalecem a descontinuidade nas ações programadas e a falta de planejamento nas ações preventivas.

A continuidade garante um maior conhecimento dos agentes em relação às áreas de risco e à população vulnerável a estes riscos, além do aumento da confiança da população em relação aos agentes já conhecidos. A instituição deve estar preparada para atuar em curto, médio e longo prazo, estreitando relações com a população e com instituições parceiras e, dessa forma, reduzindo os riscos. De acordo com Queiroz apud Queiroz e Bodstein (2011, p.18):

A criação de uma carreira em Defesa Civil asseguraria a continuidade dos esforços, minimizando e, eventualmente, erradicando o impacto dos interesses políticos passageiros, que não se pretendem maiores do que a duração de um mandato eleitoral.

Desta forma, não apenas a formação é importante, mas também a continuidade das atividades, independentemente da mudança de secretários, prefeitos e governadores. 
Para Ganem (2012), o Sistema Nacional de Proteção e Defesa Civil enfrenta falta de quadros técnicos estáveis e treinados, especialmente na realização das ações de prevenção a desastres. De acordo com Queiroz apud Queiroz e Bodstein (2011, p.18).

A atual Política Nacional de Defesa Civil (PNDC), não obstante os avanços por ela consignados, não logrou instrumentalizar uma visão integrada do objeto e das praticas da Defesa Civil, criando uma estrutura piramidal cuja base é extremamente frágil. Em todos os níveis de atuação e principalmente na base desta pirâmide, há necessidade de um maior nível de capacitação técnico-profissional dos atores bem envolvidos, o que não poderá ser feito sem a criação de uma carreira estruturada e bem definida em seus objetivos políticos e sociais.

A busca de uma identidade ainda não bem definida quanto à hierarquia, atribuições e tipos de vínculo torna-se mais complexa quando consideramos as pessoas envolvidas. Nos questionários respondidos por agentes de defesa Civil neste trabalho e em entrevistas com comunidades atendidas pela Defesa Civil (Londe et al., 2014) percebemos a falta de uma definição clara de quem faz parte da Defesa Civil.

Como exemplo, estudantes residentes em áreas de risco de desastres em Campos do Jordão - SP (Londe et al., 2014) não conhecem as atribuições da Defesa Civil e, em sua maioria, desconhecem o número de telefone da Defesa Civil para emergências, instigando a necessidade de um longo trabalho de promoção da interação entre Defesa Civil e população, para que esta se reconheça de fato como parte do sistema de proteção e defesa civil, principalmente em municípios que apresentam áreas de risco de desastres naturais, como o caso de Campos do Jordão e muitos outros.

A divisão de Comunicação Social da Defesa Civil de São Paulo trabalha neste direcionamento com o lema "A Defesa Civil somos todos nós e ninguém é melhor do que todos nós juntos".

[...] fica bem evidente que as ações de prevenção, preparação e resposta aos desastres e de recuperação, mais que um direito, são um dever da população, do cidadão, da comunidade e, portanto, da sociedade (entendida esta como o conjunto dos diferentes estratos da população, incluindo o governamental). (BRASIL, 2007)

O trabalho de informação, orientação e capacitação, reconhecido como atribuição da Defesa Civil por aproximadamente $18 \%$ dos entrevistados (Figura 2A), idealmente deveria ser realizado ou supervisionado por profissionais como psicólogos, sociólogos, geógrafos e pedagogos. Poucos entrevistados, porém, mencionaram a necessidade de profissionais para ações não estruturais (Figura 3A). A maioria indicou a necessidade de arquitetos, engenheiros e geólogos (Figura 3A), o que aponta a preocupação de compor um corpo técnico-científico para avaliar os riscos de movimento de massa e a condição estrutural das casas.

Neste aspecto, é importante ressaltar que a avaliação de riscos, além de profissionais especializados, demanda também outros recursos e instrumentos, como o Plano Diretor com especificação das áreas de risco, com respaldo nas cartas geotécnicas e topográficas. Conforme Figura 4C, os municípios vêm tendo acesso aos mapas de áreas de risco (inundação ou deslizamento). Entretanto, apenas 3,53\% (197) dos 5.570 municípios 
brasileiros possuem a carta geotécnica de aptidão à urbanização, instrumento de ordenamento do espaço urbano (MUNIC/IBGE 2014).

$\mathrm{Na}$ avaliação de riscos é preciso também contar com viaturas e combustível para deslocamento até os locais a serem monitorados, uniformes, equipamentos de proteção, entre outros. A base para atuação da Defesa Civil é uma disponibilidade adequada de recursos para a execução de suas atividades e o seu fortalecimento institucional. Porém, $88 \%$ dos entrevistados consideram o repasse de recursos financeiros inadequados ou inexistentes (Figura 4A).

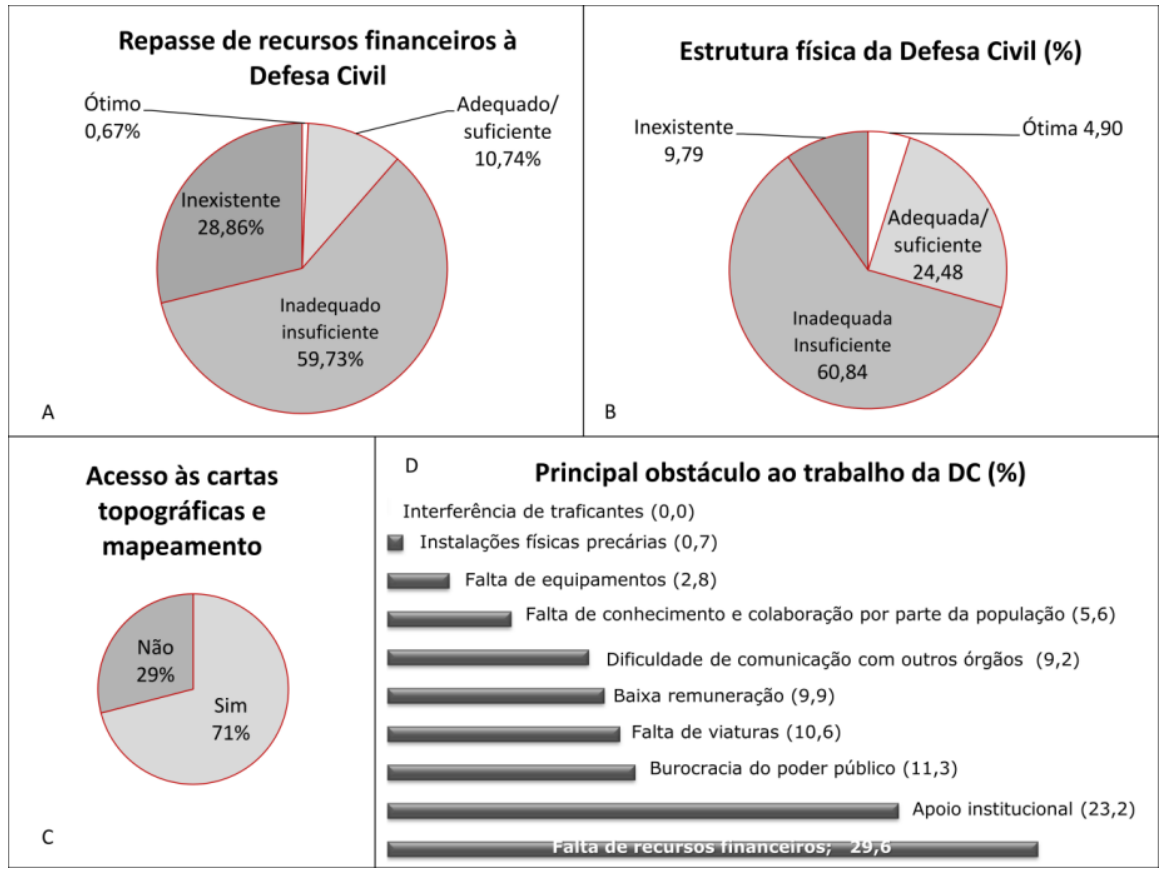

FIGURA 04: Respostas relacionadas à identidade institucional. Reprodução completa do questionário no Anexo l, questões 4 (a), 5(b), 14(c) e 19(d).

A insuficiência de recursos compromete os serviços prestados à população, como a reversão de cenários de vulnerabilidade e ações de fiscalização, mobilização e mitigação dos prejuízos humanos e materiais de eventos adversos.

É igualmente interessante a contraposição ao percentual acima: $11 \%$ consideram os recursos disponíveis adequados e 1\% consideram excelentes. Entende-se por estas respostas que existem órgãos locais de Defesa Civil com recursos suficientes para o desenvolvimento das atividades e das práticas de prevenção, ação e mitigação, mas que são casos bem específicos e não representam a condição da imensa maioria das defesas civis no país.

Com relação à estrutura física e equipamentos disponíveis, 5\% e $25 \%$ avaliam a estrutura da DC como ótima e adequada, respectivamente (Figura 4B). Por outro lado, $60 \%$ e $10 \%$ consideram a estrutura inadequada e inexistente, demonstrando a precariedade nas condições de trabalho da maioria dos entrevistados (Figura 4B).

Considerando-se que a Defesa Civil é o principal órgão para agir, em tempo hábil, numa situação de desastre, estes valores são extremamente significativos, pois motivam uma reflexão sobre a importância conferida à instituição por parte dos administradores municipais. 
Conforme Soriano et al. (2013), grande parte dos candidatos a prefeituras de municípios com histórico de desastre nos estados de São Paulo e Rio de Janeiro não citou a Defesa Civil em seus planos de governo (eleições municipais de 2012), expondo a fragilização de políticas sociais e da instituição de uma forma geral e, principalmente, sua extensão municipal, a Coordenadoria Municipal de Proteção e Defesa Civil (COMPDEC).

Para os representantes de Defesa Civil que responderam ao questionário, questões comumente apontadas como as maiores dificuldades enfrentadas pelo órgão em seu nível local, como falta de equipamentos, instalações físicas precárias e baixa remuneração não foram apontados como os principais obstáculos para a realização dos trabalhos. Destaca-se como obstáculos, entretanto, a falta de recursos financeiros e de apoio institucional, com 29,6 e $23,2 \%$ das respostas, respectivamente (Figura 4D).

Partindo da premissa de que há desigualdades nos apoios oferecidos às COMPDECs, procuramos identificar o que pensam os agentes sobre o apoio do poder público em suas diferentes esferas: municipal, estadual e federal (Figuras 5A, 5B e 5C).

As Figuras 5A, 5B e 5C ilustram uma situação onde os interesses e discursos dos órgãos públicos não se coadunam. Impressiona o fato de $54 \%$ dos que responderam ao questionário afirmarem que o apoio do município é inadequado para a realização das atividades da Defesa Civil (Figura 5A): além das dificuldades já apresentadas anteriormente, os agentes não têm o apoio adequado do órgão público ao qual estão diretamente subordinados. Destaca-se, de forma negativa, que para $3 \%$ o apoio é inexistente.

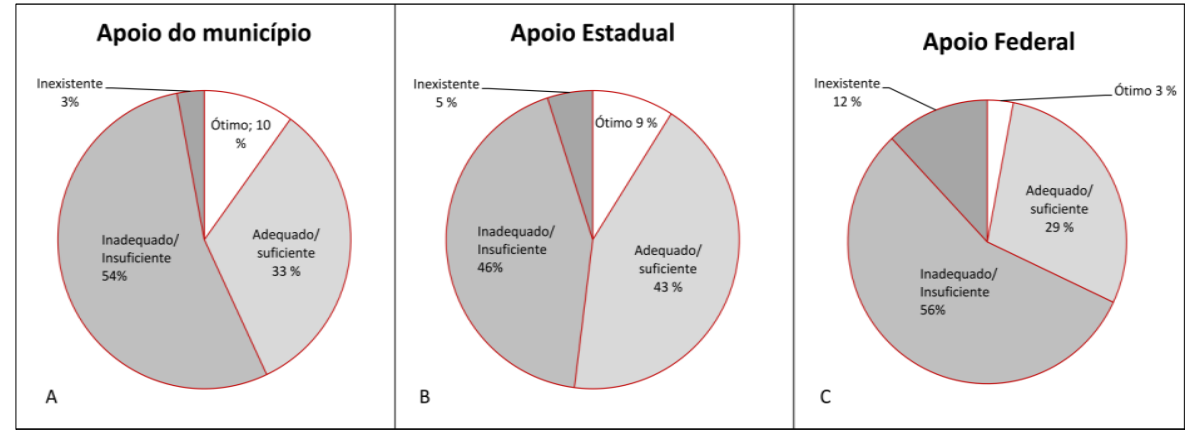

FIGURA 05: Respostas relacionadas à identidade institucional. Reprodução completa do questionário no Anexo l, questões 7 (a), 8(b) e 9(c).

Ainda de acordo com a Figura 5C, o apoio avaliado positivamente em nível federal alcançou percentual menor do que nos níveis municipal e estadual. Entende-se, neste aspecto, que o Estado está institucionalmente mais próximo do município, oferecendo ajuda com equipe de apoio e suporte de outras instituições e fornecendo materiais de socorro e assistência aos afetados.

Outra fragilidade institucional da defesa civil corresponde aos níveis de governo e aos entraves burocrático-partidários que dificultam a representação homogênea do órgão em todas as regiões. Cabe aos órgãos estaduais reportarem situação de anormalidade à Secretaria Nacional de Defesa Civil (SEDEC).

Porém, em muitos casos, os membros das Secretarias Estaduais são bombeiros, ou seja, têm função de proteção civil, mas são militares e respondem ao governador dos seus estados (SORIANO, 2012). O mesmo se observa em relação às esferas municipais de defesa civil, 
onde os agentes ou são bombeiros e respondem ao governador e à SEDEC, ou são Guardas Municipais respondendo ao prefeito municipal. Estas situações se complicam quando se observa alguma disputa partidária entre as esferas de governo, assim como não se observa uma homogeneidade de formações e interesses nos diferentes níveis de defesa civil. (SORIANO, 2012).

Segundo relatório de auditoria do Tribunal de Contas da União (TCU, 2010) sobre o funcionamento do Sistema Nacional de Defesa Civil, o desconhecimento sobre a legislação relativa à transferência de recursos para ações de resposta aos desastres e a pouca capacidade técnica para elaborar planos de trabalho em conformidade com as exigências legais, atrasaram a liberação dos recursos federais, afetando a eficácia dessas intervenções.

Porém, mesmo com a correta alocação de recursos, falta participação da população, inclusive nas decisões importantes e planejamento de estratégias e ações. Deve haver participação plena, consciente e eficiente (BRASIL, 2007), especialmente na fase de planejamento, prevenção e simulação.

Os principais efeitos decorrentes da baixa institucionalização dos órgãos de defesa civil são o desconhecimento dos envolvidos sobre a forma de atuação relacionada à ocorrência de desastres, assim como a indefinição de responsabilidades e atribuições. Igualmente, há falta de planejamento de ações de prevenção necessárias para evitar ou minimizar os efeitos provocados por situações de emergência ou calamidade pública (TCU, 2010).

As dificuldades mencionadas convergem para um tema crucial em todas as etapas da gestão de riscos de desastres: a comunicação. De acordo com as respostas ao questionário, a comunicação é melhor entre o município e estado: 85 \% dos municípios a considera como ótima (24 \%) e adequada (61 \%) (Figura 6B).

Quando se analisa a ligação do município com a esfera federal, representada na pesquisa pelo Centro Nacional de Gerenciamento de Riscos e Desastres (CENAD) e Centro Nacional de Monitoramento e Alerta de Desastres Naturais (CEMADEN), houve menos respostas "adequada" e "ótima" em comparação com a comunicação com o estado, sendo as respostas semelhantes para os dois centros, conforme Figuras 6C e 6D.

Atualmente, o sistema de alerta e comunicação entre órgãos do Sistema Nacional de Proteção e Defesa Civil, em nível federal segue a Portaria SEDEC/MI n³14/2012, que prevê uma comunicação permanente entre o CEMADEN e CENAD, assim como em relação às instituições estaduais e municipais.

Cabe observar a importância do "feedback" do município ao CENAD e CEMADEN para o aprimoramento do sistema de alertas, pois somente a partir de uma inspeção local e retorno de informações será possível avaliar a eficiência/confiabilidade do alerta.

Merece destaque a comunicação entre os municípios, através da Defesa Civil ou de outros órgãos, principalmente em relação aos riscos hidrológicos, pois municípios pertencentes à mesma bacia hidrográfica têm benefício mútuo com a troca de informações. A comunicação entre voluntários e a Defesa Civil também é enriquecedora e deveria ser incentivada em diferentes esferas de atuação. 


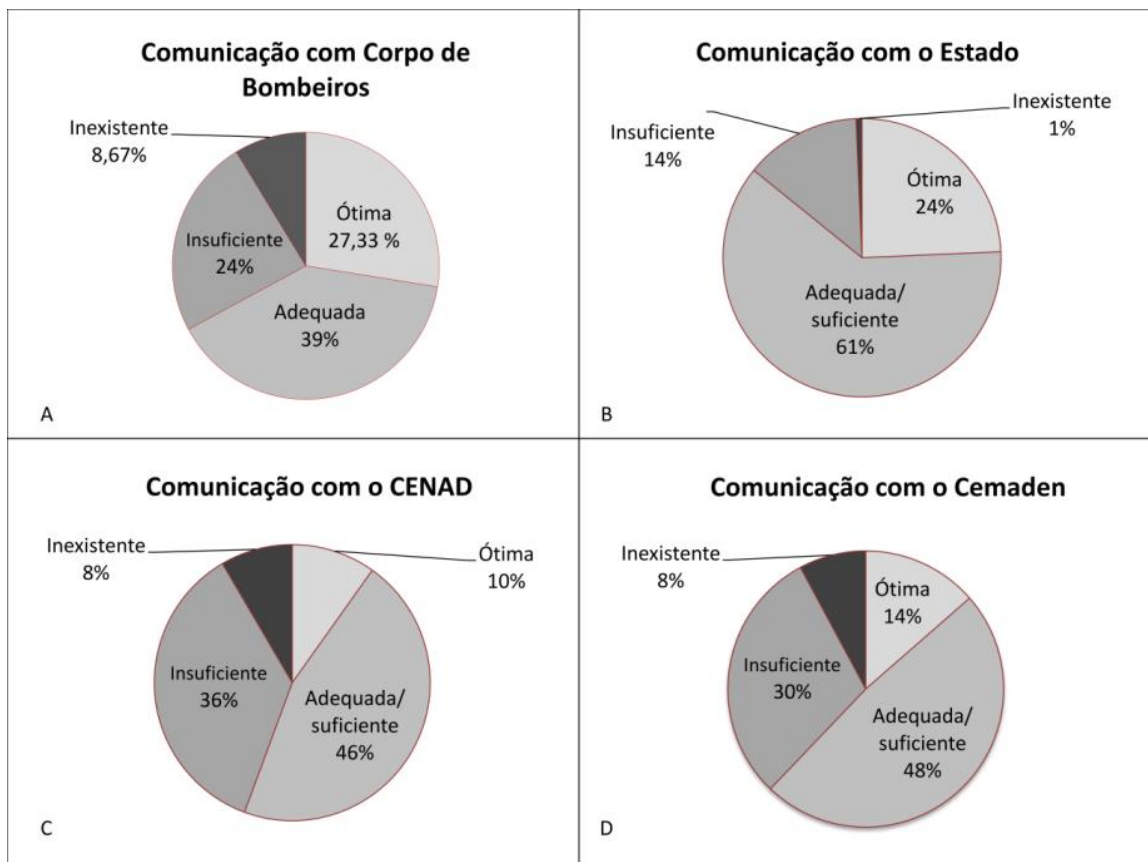

FIGURA 06: Respostas relacionadas à identidade institucional. Reprodução completa do questionário no Anexo I, questões 10 (a), 11(b), 12(c) e 13(d).

Atualmente, todo processo de comunicação de danos e decretos de estado de emergência ou calamidade pública pode ser feito pela internet, por meio do Sistema Integrado de Informações sobre Desastres - S2ID, que é um sistema com objetivo de informatizar os procedimentos para a solicitação de reconhecimento de Situação de Emergência ou de Estado de Calamidade Pública e o processo de transferência de recursos federais para Estados ou Municípios afetados por desastres.

O uso de ferramentas tecnológicas nas suas ações da Defesa Civil facilita o trabalho de profissionais e agiliza o processo de tramitação, desde que a Defesa Civil tenha uma infraestrutura mínima, como um computador e acesso a internet.

Uma adequada comunicação também é desejada entre a Defesa Civil e a população, caracterizando-se como medida essencial para minimizar os impactos de eventos adversos. Para fortalecer as medidas de redução de riscos de desastres, processo ainda incipiente no Brasil, é preciso fortalecer também a participação comunitária, pois toda gestão de risco tem início na localidade em que os desastres acontecem (UFSC/CEPED, 2012). De acordo com Valencio (2009, p.28):

É passado o tempo no qual as recomendações da peritagem em defesa civil, no Brasil, eram de que não se falasse em desastre com comunidades em risco para não alarmá-la e gerar pânico e convulsão social. A orientação hodierna, sobretudo nos fóruns multilaterais que produzem importantes protocolos para ações de proteção civil em cenário de desastre (como o Projeto Esfera) denota que, quão mais envolvidos estiverem os atores locais na formulação e implementação das estratégias, menores são os danos causados por desastres e mais legitimamente os órgãos de defesa civil passam a atuar. Por exemplo, quando o agente de defesa civil ajuda a comunidade a construir consensos em torno de medidas de prevenção às enchentes ou deslizamentos, mais motivadas as lideranças comunitárias 
estarão para atuar junto aos respectivos conselhos municipais, representantes do legislativo e do executivo, dentre outros mecanismos, para cobrar a realização de obras de melhoria de drenagem, contenção de encostas e demais medidas que protejam sua população, assim como tomam para si as tarefas que lhe competem na sua própria segurança.

Somente através de um inteligente e bem estruturado esforço de ampla informação e motivação da população pode ser alcançada uma real mudança cultural (BRASIL/MI, 2007). Entretanto, quando se observa os municípios que possuem Núcleos Comunitários de Defesa Civil (NUDECs), conforme Perfil Municipal do IBGE, apenas 8,29 \% (462) dos 5.570 possui NUDECs, o que evidencia a baixa capacidade de organização dos atores locais e estrutura da DC.

Moura (2011) analisou a percepção de moradores em áreas vulneráveis a desastres naturais do município do Guarujá: ao indagar quais atitudes tomariam de imediato durante algum evento de risco, $81 \%$ das pessoas responderam que sairiam de suas casas e procurariam um lugar seguro para se abrigar. A referida autora entende que esse alto percentual de respostas se deve ao longo trabalho de conscientização da Defesa Civil com os moradores de áreas de risco, baseados no Plano Municipal de Redução de Desastres (PMRR) e de iniciativas da prefeitura de incorporar como temas transversais em todas as escolas municipais a questão da educação ambiental e desastres socioambientais.

$\mathrm{Na}$ cidade de Santos, "por meio da defesa civil, foi realizado um intenso treinamento para desocupação dos morros em caso de chuvas fortes. O resultado foi expressivo: durante anos não foram registradas mortes por escorregamento das encostas da Serra do Mar" (RIBEIRO, 2008).

Os trabalhos mencionados reforçam a necessidade do estreitamento de relações entre a Defesa Civil e as comunidades. Além do envolvimento da sociedade, há um desafio de aperfeiçoamento das relações inter-institucionais no âmbito da Defesa Civil. Como exemplo, a defesa Civil é responsável pela fiscalização das áreas de risco devendo evitar novas ocupações em tais áreas, mas quando áreas de risco coincidem com áreas de preservação, tem-se sobreposição de atribuições dos órgãos ambientais com a Defesa Civil. Nesse caso, a fiscalização conjunta ou compartilhada seria indicada para a otimização de gastos.

\section{CONCLUSÃO}

As instituições de Proteção e Defesa Civil passam por um processo de reconhecimento e valorização da identidade institucional, ainda permeado por dúvidas sobre a melhor composição do quadro de funcionários, o vínculo empregatício mais adequado e a hierarquia desejada. A escassez de recursos não é vista como principal dificuldade e um apoio institucional efetivo, de acordo com as respostas, seria o principal propulsor do trabalho da Defesa Civil.

Assim como a instituição e seus profissionais vêm construindo aos poucos esta identidade, com a identificação das ações pertinentes e parcerias necessárias, as Prefeituras igualmente passam por um processo de reconhecimento da necessidade e importância dos órgãos locais de Defesa Civil. Apesar de os desastres não serem um problema recente no país, as medidas 
de prevenção e resposta ganharam corpo nos últimos anos e os órgãos públicos estão ainda em adaptação, tanto nos aspectos legais quanto na execução efetiva.

Cabe aos gestores municipais tomar conhecimento da Lei $12.608 / 2012$ e prover a Defesa Civil com agentes e recursos compatíveis com as necessidades de seu município, acompanhado suas atividades e facilitando a interação com outros órgãos e instituições.

A comunicação eficiente em suas várias esferas e o envolvimento com a comunidade são temas que ainda não são considerados essenciais, apesar de sua inegável importância para o funcionamento efetivo da Defesa Civil dentro de sua concepção de órgão de prevenção e enfrentamento de desastres. A participação das comunidades, não só daquelas residentes em áreas de risco, é o maior e mais importante desafio da Defesa Civil: o sistema de Proteção e Defesa Civil somente será eficiente quando tiver a sociedade como aliada.

\section{BIBLIOGRAFIA}

BRASIL, Ministério da Integração Nacional (MI), Secretaria Nacional de Defesa Civil (SEDEC). Conferência geral sobre desastres: para prefeitos, dirigentes de instituições públicas e privadas e líderes comunitários. Brasília: MI., 2007. 23 p. Disponível em: http://www.integracao.gov.br/c/document library/get file?uuid=8cc85f7e-ede2-4ec39792-748f68f5bbbf\&groupld=10157. Acesso em: 11 jul. 2014.

BRASIL. Presidência da República Casa Civil- Subchefia para Assuntos Jurídicos. Lei no 12.608, de 10 de abril de 2012. Institui a Política Nacional de Proteção e Defesa Civil - PNPDEC.... Disponível em: http://www.planalto.gov.br/ccivil 03/ Ato20112014/2012/Lei/L12608.htm. . Acesso em: 18 jul. 2014

BRAUN, A.A. A Análise do trabalho voluntariado no Sistema Nacional de Defesa Civil. 2006. 39 f. Trabalho de Conclusão de Curso (Especialização em Planejamento e Gestão em Defesa Civil)-Universidade Federal de Santa Catarina - UFSC, Florianópolis.

ESTRATÉGIA INTERNACIONAL PARA REDUCCIÓN DE DESASTRES DE LAS NACIONES UNIDAS (UN/ISDR). Terminología sobre reducción del riesgo de desastres. Ginebra, Suiza: UM/ISDR, 2009. Disponível em: http://www.unisdr.org/publications/. Acesso em: 26 fev. 2013.

GANEM, R.S. Gestão de desastres no Brasil. Estudo. Consultoria Legislativa. Câmara dos Deputados, Anexo III, Praça dos 3 Poderes, Brasília-DF. Disponível em: http://www2.camara.leg.br/documentos-e-

pesquisa/publicacoes/estnottec/tema14/2012 16213.pdf. Acesso 11/04/2013.

GORGULHO, S. Eventos extremos e a gestão de recursos hídricos. Secas e inundações afetam a vida de um terço da população da Terra. Folha do Meio Ambiente. Brasília, maio de 2006, p.18 $22 . \quad$ D 22 em $\quad$ http:// http://www.folhadomeio.com.br/publix/fma/folha/2006/05/eventos168.html/. Acesso em: 09 de Abr. de 2009.

IPT. A tecnologia a serviço da Gestão de Riscos: a experiência do Instituto de Pesquisas Tecnológicas - IPT, em São Paulo. Centro de Tecnologias Ambientais e Energéticas CETAE/Laboratório de Riscos Ambientais - LARA. Disponível em:

MINISTÉRIO DA INTEGRAÇÃO NACIONAL (MI) SECRETARIA NACIONAL DE DEFESA CIVIL. Portaria no 314, de 17 de outubro de 2012. Disponível em: http://pesquisa.in.gov.br/imprensa/jsp/visualiza/index.jsp?data=19/10/2012\&jornal=1 \&pagina=26\&totalArquivos=140. Acesso em: 17 jul. 2014 
LONDE, Luciana de Resende, SORIANO, Érico, COUTINHO, Marcos Pellegrini, MARCHEZINI, Víctor. 'interpretação do risco de desastres naturais por alunos de ensino fundamental e médio'. Revista do Departamento de Geografia. , v.27, p.315 - 341, 2014.

MOURA, E.F. Percepção de risco em área de população vulnerável a desastres naturais do município de Guarujá-SP. Dissertação (Mestrado), Universidade Estadual de Campinas, Instituto de Geociências. 2011, 88 f.

MUNIC/IBGE _ Perfil dos municípios brasileiros 2013. Rio de Janeiro: IBGE, 2014. 285 p. Acompanha 1 CD-ROM. Acima do título: Pesquisa de Informações Básicas Municipais. Disponível

em:

http://www.ibge.gov.br/home/estatistica/economia/perfilmunic/defaulttab1 perfil.shtm. Acesso em: out. 2014.

QUEIROZ, E.; BODSTEIN, A. Território e Bacias Hidrográficas: reflexões a propósito da gestão de recursos hídricos e seus possíveis desdobramentos sobre as práticas de Defesa Civil frente aos desastres de origem hídrica. Revista Científica Internacional. Nova lorque, n.16, jan-mar, 2011.

RIBEIRO, Wagner Costa. Impactos das mudanças climáticas em cidades no Brasil. Parcerias Estratégicas, 2008, v. 27, p. 297-321.

SORIANO, E. et al. Avaliação de propostas de candidatos a prefeitos em relação aos riscos de desastres naturais. Soc. e Nat., Uberlândia, 25 (3): 525-542, set/dez/2013. Disponível em: http://www.scielo.br/scielo.php?script=sci arttext\&pid=S1982-

45132013000300007\&lng=pt\&nrm=iso\&tlng=pt. Acesso em: 11 jul. 2014

SORIANO, E. Confiança, incertezas e discursos sobre os riscos de colapso de barragem na UHE Itaipu Binacional: o processo de vulnerabilização dos moradores a jusante. 2012. 184f. Tese (Doutorado em Ciências da Engenharia Ambiental). Programa de Pós- Graduação em Ciências da Engenharia Ambiental, Universidade de São Paulo, São Carlos. 2012

TCU. Secretaria de Fiscalização e Avaliação de Programas de Governo (Seprog). Auditoria Operacional: Sistema Nacional de Defesa Civil. Disponível em: http://portal2.tcu.gov.br/portal/page/portal/TCU/comunidades/programas governo/ar eas atuacao/seguranca publica/Folder Sistema\%20Nacional\%20de\%20Defesa\%2 0Civil.pdf. Acesso 10 jul. 2014.

UFSC/CEPED- Universidade Federal de Santa Catarina. Centro Universitário de Pesquisa e Estudos sobre Desastres. Capacitação básica em Defesa Civil. Textos: FURTADO, J.; OLIVEIRA, M.de; DANTAS, M.C.; SOUZA, P.P.; PANCERI, R. Florianópolis: CAD/UFSC, 2013. 122 p.

UFSC/CEPED- Universidade Federal de Santa Catarina. Centro Universitário de Pesquisa e Estudos sobre Desastres. Capacitação dos gestores de Defesa Civil para uso do Sistema Integrado de Informações sobre Desastres - S2ID / [Texto: Jairo Ernesto Bastos Krüger]. Florianópolis: CAD UFSC, 2012. 112 p. : $30 \mathrm{~cm}$.

VALENCIO, N. O Sistema Nacional de Defesa Civil (SINDEC) diante das mudanças climáticas: desafios e limitações da estrutura e dinâmica institucional. In: N. Valencio; M. Siena; V. Marchezini; J.C. Gonçalves. (Org.). Sociologia dos Desastres: construção, interfaces e perspectivas no Brasil. 1 ed. São Carlos: RiMa, 2009, v. 1, p. 19-33.

VALENCIO, N.F. L da S; VALENCIO, A. O Processo de Vulnerabilização de Populações Inseridas à Jusante de Barragens no Brasil: apontamentos sociológicos para catástrofes anunciadas. In: V ENCONTRO NACIONAL DA ANPPAS. Florianópolis, 2010. Anais do V Encontro Nacional da ANPPAS. Florianópolis: ANPPAS, 2010. 


\section{Pesquisa com órgãos de Defesa Civil Municipal}

Agradecemos por colaborar conosco nesta pesquisa, cujo objetivo é avaliar a atual situação dos órgãos municipais de Defesa Civil no Brasil.

Lembramos que em nenhum momento você será identificado e não haverá identificação de sua localização. As respostas serão tratadas de forma confidencial.

Quando chegar ao final do questionário, por favor clique em "enviar". Obrigado!

* Obrigatorio

1 - Marque todas as opções que você considera, de fato, atribuições da Defesa Civil Municipal:

poda de árvores

$\square$ interdição de construções inseguras ou construídas em áreas de risco

$\square$ remoção da população de áreas de risco

$\square$ organização de recursos para situaçòes de emergência ou calamidade (colchòes, alimentos, abrigo temporário, etc.)

$\square$ acompanhamento e orientação da população

$\square$ resgates e salvamentos

manutenção da ordem nas praias

outras

2 - Seu município possui Guarda Municipal? *

SIM

NÃO

3 - Você acredita que as pessoas confundem as atribuições da Defesa Civil com as da Guarda Municipal? *

SIM

NÃO 
Ótimo

Adequado/suficiente

Inadequado/insuficiente

Inexistente

5-Como você qualifica as instalações/estrutura física, móveis e equipamentos disponíveis para o trabalho da DC de seu município? *
Q Ótimos
Adequados/suficientes
(1) Inadequados/insuficientes
Inexistentes

6 -Marque quais dos profissionais abaixo fazem parte da Defesa Civil do seu município: *
Arquiteto
Meteorologista
Geólogo
Profissional de logistica
Psicólogo
Geógrafo
Engenheiro Civil
Sociólogo
Nenhum

7 - Como você qualifica o apoio oferecido pela Prefeitura à Defesa Civil municipal? *

Ótimo

Adequado/suficiente

Inadequado/insuficiente

Inexistente 


\section{8 - Como você qualifica o apoio oferecido pelo Governo}

Estadual à Defesa Civil municipal? *
Ótimo
- Adequado/suficiente
Inadequado/insuficiente
Inexistente

9 - Como você qualifica o apoio oferecido pelo Governo Federal à Defesa Civil municipal? *
O Ótimo
- Adequado/suficiente
- Inadequado/insuficiente
Inexistente

10-Como você qualifica a comunicação entre a Defesa Civil municipal e o corpo de bombeiros local? *

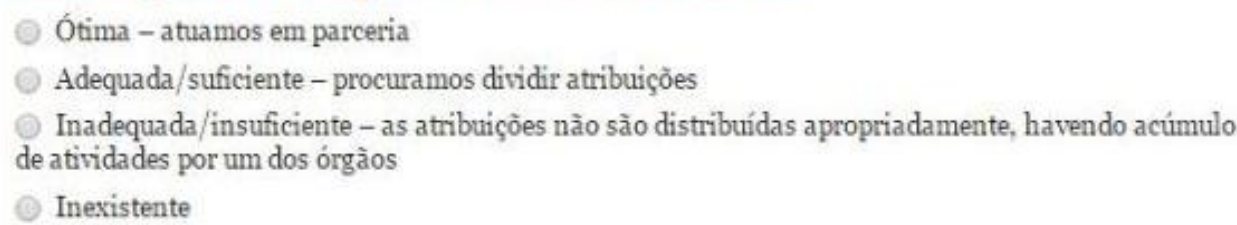

11 - Como você qualifica a comunicação entre a Defesa Civil municipal e a Defesa Civil estadual? *
Ótima
Adequada/suficiente
Inadequada/insuficiente
Inexistente

12 - Como você qualifica a comunicação entre a Defesa Civil municipal e o CENAD? *
Ótima
Adequada/suficiente
Inadequada/insuficiente
Inexistente
Nào conheço/nào sei o que é CENAD 


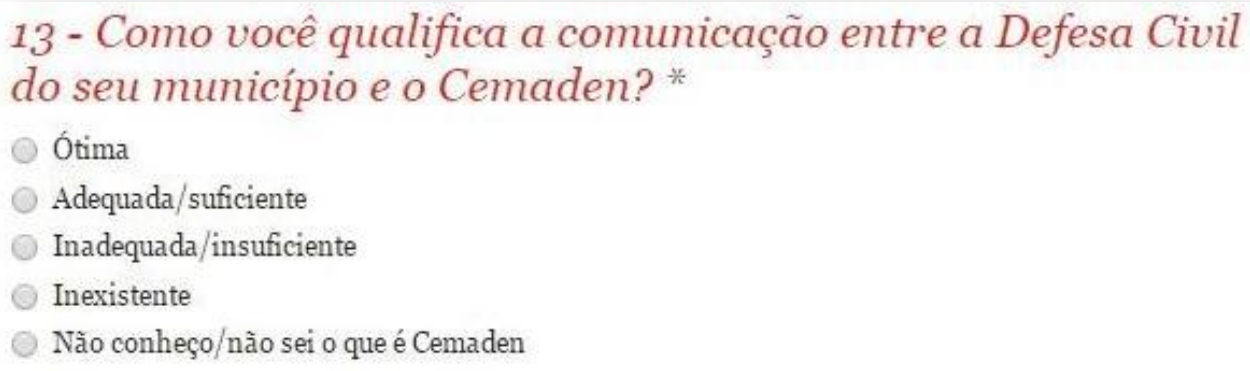

14 - A Defesa Civil do seu município tem acesso às cartas topográficas e mapas de áreas de risco do município? *
SIM
NÃO

15-Em alguns municípios, os cargos de chefe e/ou diretor de Defesa Civil são cargos comissionados e, portanto, o quadro de profissionais da DC sofre frequentes alterações. Em sua opinião: *

a atribuição de cargos por indicação está correta e as alterações do quadro de profissionais trazem benefícios à atuação da Defesa Civil.

a atribuição de cargos por indicação está incorreta e as alterações do quadro de profissionais trazem prejuízos à atuação da Defesa Civil. Todos os cargos deveriam ser preenchidos através de concurso público.

16- Em sua opinião, o órgão de DC municipal deveria estar subordinado: *

- Diretamente à Prefeitura Municipal

(- À instituiçào militar de seu município

Ao corpo de bombeiros

- À Secretaria de Meio Ambiente

Ao Departamento de Trânsito Municipal

A DC Municipal deveria ser independente (não deveria vincular-se a outros órgãos)

Outro 
17 - Considerando a inserção em locais de difícil acesso, com graves problemas socioeconômicos, você precisa ter algum tipo de contato com traficantes e/ou representantes de crime organizado para realizar seu trabalho na Defesa Civil? *
SIM
ก NÃO

18- Caso tenha respondido "sim" na questão anterior, como você qualifica esta necessidade?

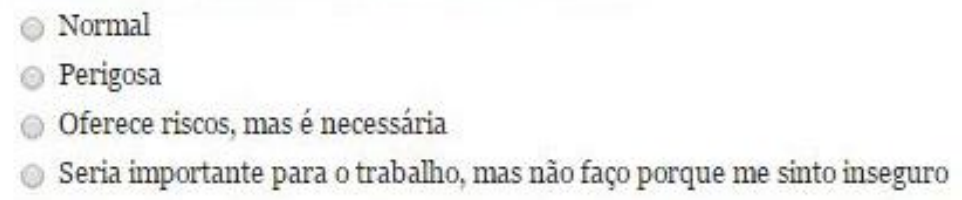

19-Qual você considera o principal obstáculo ao seu

trabalho na DC? (Marque apenas o problema mais grave) *

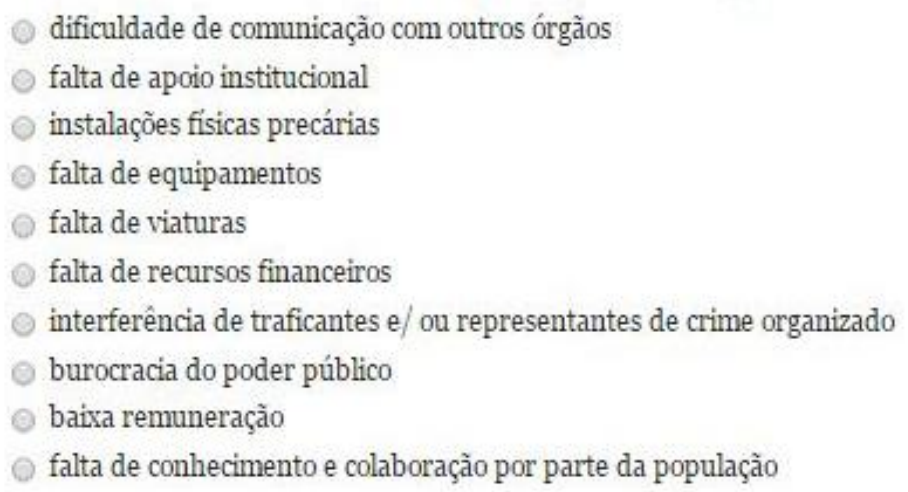

20 - Qual é o seu vínculo empregatício com a Defesa Civil Municipal? *

Concurso Público

Cargo comissionado

Agradecemos mais uma vez por sua valiosa participação nesta pesquisa! Se você dispuser ainda de mais alguns minutos, pedimos que comente abaixo o que poderia melhorar o trabalho da Defesa Civil Municipal. Em seguida, por favor clique em "ENVIAR". Obrigado! 